\title{
On the Stabilization of Carbanions by Adjacent Phenyl, Cyano, Methoxy-carbonyl, and Nitro Groups in the Gas Phase
}

\author{
Renée A. L. Peerboom, Leo J. de Koning, and Nico M. M. Nibbering \\ Institute of Mass Spectrometry, University of Amsterdam, Amsterdam, The Netherlands
}

\begin{abstract}
By using the method of Fourier transform ion cyclotron resonance mass spectrometry, substituent stabilization energies of homologous series of cycloalkyl carbanions, $X_{-}-c-C_{n} H_{2 n-2}$ $(n=3,4,5,6,7)$ with $\pi$-accepting substituents $\left(X=P h, C N, C O O M e, \mathrm{NO}_{2}\right)$ have been determined experimentally in the gas phase as the difference between the proton affinity of the substituted and corresponding unsubstituted $(\mathrm{X}=\mathrm{H})$ cycloalkyl carbanions.

The stabilization energy data have been analyzed in terms of Taft's parametrization of polarizability, field/inductive, and resonance effects. The linear regression analyses show excellent correlations within the $\left.\mathrm{XCH}_{2}^{-}, \mathrm{X}-\mathrm{c}-\mathrm{C}_{\mathrm{n}} \mathrm{H}_{2 \mathrm{n}-2}^{-} \mathrm{(n}=4,5,6,7\right)$, and $\mathrm{X}-\mathrm{c}-\mathrm{C}_{3} \mathrm{H}_{4}^{-}$carbanion series, from which it appears that the contributions of polarizability effects are independent of the above type of carbanions and only depend on the nature of the substituent.

Further, it follows that inductive stabilization is more effective in the substituted methyl, $\mathrm{XCH}_{2}^{-}$, than in the substituted cycloalkyl, $\mathrm{X}-\mathrm{c}-\mathrm{C}_{\mathrm{n}} \mathrm{H}_{2 \mathrm{n}-2}-(\mathrm{n}-4,5,6,7)$ carbanions. This result suggests that inductive stabilization is counteracted by the electron releasing effect of alkyl groups.

Resonance stabilization is significantly more effective in the substituted cycloalkyl, $\mathrm{X}-\mathrm{c}$ $\mathrm{C}_{\mathrm{n}} \mathrm{H}_{2 \mathrm{n}-2}^{--}(\mathrm{n}=4,5,6,7)$, than in the substituted methyl, $\mathrm{XCH}_{2}^{-}$, carbanions, which suggests that in contrast to inductive stabilization, resonance stabilization is assisted by the electron releasing effect of alkyl groups.

Finally, it appears that substitutent stabilization in the geometrically restricted substituted cyclopropyl carbanions, $\mathrm{X}-\mathrm{c}-\mathrm{C}_{3} \mathrm{H}_{4}^{-}$, is dramatically less effective than in the corresponding geometrically unrestricted larger substituted cycloalkyl carbanions, $X-c-C_{n} \mathrm{H}_{2 n-2}(n=$ $4,5,6,7)$. The linear regression analyses of the substituted cycloalkyl carbanions indicate that reduction of the stabilization energy is caused not exclusively by a geometrically hindered resonance stabilization, but also to a smaller extent by a less efficient inductive stabilization in the substituted cyclopropyl carbanions. (J Am Soc Mass Spectrom 1994, 5, 159-168)
\end{abstract}

$\mathrm{S}$ tabilization of carbanions by $\alpha$-substitutents has become a continual topic in physical organic chemistry. In recent years the intrinsic properties of $\alpha$-substituted carbanions have been probed by numerous theoretical studies [1-22] from which it appears that stabilization is the resultant of a trade-off between resonance, inductive, polarizability, and lone-pair electron repulsion effects. In general, the available experimental gas-phase data, although limited and scattered, seem to support the above theorization.

A systematic flowing afterglow (FA) study [19] on 1-substituted allyl carbanions shows that electronwithdrawing and $\pi$-donating substitutents $(\mathrm{F}, \mathrm{OMe}$, $\mathrm{NMe}_{2}$ ) do not destabilize the allyl anion by increasing its basicity, but rather by decreasing its electron-binding energy, whereas second-row substituents ( $\mathrm{Cl}, \mathrm{SMe})$

Address reprint requests to Prof. Nico M. M. Nibbering, Institute of Mass Spectrometry, University of Amsterdam, Nieuwe Achtergracht 129, 1018 WS Amsterdam, The Netherlands. stabilize the allyl anion by both lowering its basicity and increasing its electron-binding energy. Similarly, but more effectively, the allyl anion is stabilized by $\pi$-accepting substituents $\left(\mathrm{C}_{2} \mathrm{H}_{3}, \mathrm{Ph}, \mathrm{CN}, \mathrm{CHO}\right) . \mathrm{Ab}$ initio calculations [19] reveal that the geometry of the substituted allyl anions varies considerably as a result of compensating factors associated with the different (de)stabilizing effects.

To gain insight in the relationship between geometry and stabilization of $\alpha$-substituted carbanions, a systematic study has been undertaken involving geometrically restricted carbanions.

To this end, the stabilization energies of homologous series of cycloalkyl carbanions, $X-c-C_{n} H_{2 n-2}(n$ $=3,4,5,6,7)$ with $\pi$-accepting substituents $(X=P h$, $\mathrm{CN}, \mathrm{COOMe}, \mathrm{NO}_{2}$ ) have been determined experimentally as the difference between the proton affinity (PA) of the substituted and corresponding unsubstituted cycloalkyl carbanions. For this, the PA data on the cycloalkyl carbanions, $c-C_{n} H_{2 n-1}^{-}$have been taken from a previous study [23]. 
The results of this previous study [23] indicate that, except for the cyclopropyl carbanion, the cycloalkyl carbanions are significantly destabilized relative to the methyl anion. This destabilization is accounted for by the electron releasing effect of the alkyl groups. Furthermore, it is recognized that this destabilization is partially compensated by a stabilizing effect associated with the polarizability of the alkyl groups. Yet this stabilization seems to be less effective in the rigid cycloalkyl carbanions than in the acyclic alkyl carbanions probably due to the anisotropic character of the polarizability effect.

In contrast to its homologues, the cyclopropyl carbanion appears to be strongly stabilized relative to the methyl anion, from which it may be concluded that the alkyl electron releasing destabilization effect is superseded by a stabilization caused by a significant enhancement of the s-character of the lone pair orbital of the carbanion which promotes the electronegativity of the atom accommodating the negative charge.

\section{Experimental}

Experiments were performed with a Fourier transform ion cyclotron resonance (FT-ICR) mass spectrometer constructed at the University of Amsterdam and equipped with a Bruker $1.4 \mathrm{~T}$ electromagnet (Bruker Karlsruhe, Germany) and a cubic inch cell. Details of the instrument, general operating, and experimental procedures have been described previously [24].

$\mathrm{NH}_{2}{ }^{-}, \mathrm{OH}^{-}$, or $\mathrm{F}^{-}$were used as primary bases to deprotonate the compounds under study. Proton transfer equilibrium reactions involving $X-c-C_{n} H_{2 n-1}(X=$ $\mathrm{Ph}, \mathrm{CN}, \mathrm{NO}_{2}$ ) and reference compounds $\mathrm{BH}$ (see Results section) with known gas-phase acidities, $\Delta G^{\circ}$ acid were studied by monitoring the reactions of the mass selected $\mathrm{X}_{-\mathrm{c}-} \mathrm{C}_{\mathrm{n}} \mathrm{H}_{2 \mathrm{n}-\overline{2}}$ or $\mathrm{B}^{-}$ions as a function of the reaction time under equilibrium conditions. Relative acidities were obtained from eq 1.

$$
\delta \Delta G_{\text {acid }}^{o}=-R T \ln K
$$

where $R$ is the gas constant, $T$ is the absolute temperature of the reaction mixture, and $\mathrm{K}$ is the proton transfer equilibrium constant.

$$
K=\frac{\left[B^{-}\right]\left[X-c-C_{n} H_{2 n-1}\right]}{\left[X-c-C_{n} H_{2 n-2}\right][B H]}
$$

The equilibrium ion abundance ratios $\left[\mathrm{B}^{-}\right] /\left[\mathrm{X}-\mathrm{c}^{-}\right.$ $\left.\mathrm{C}_{n} \mathrm{H}_{2 \mathrm{n}-2}\right]$ were accurately determined by using the segmented Fourier transform (SEFT) procedure [25]. The equilibrium partial pressure ratios [X-c$\left.\mathrm{C}_{n} \mathrm{H}_{2 \mathrm{n}-1}\right] /[\mathrm{BH}]$ were determined from the ionization gauge manometer readings which were corrected for the relative sensitivity, $R_{X}$, of the ionization gauge manometer for gases $X$, using the relationship $R_{x}=$ $0.36 \alpha+0.30$ of Bartmess and Georgiadis [26] with polarizabilities, $\alpha$, from Miller [27]. The partial pres- sure ratios were varied between 0.25 to 4 , while the sum of the partial pressures was kept typically around $10^{-4} \mathrm{~Pa}$. The proton transfer equilibria were studied from both directions. The accuracy of the acidity determinations relative to the reference bases in the proton transfer equilibrium is estimated to be better than $3 \mathrm{~kJ}$ $\mathrm{mol}^{-1}$.

Gas-phase acidities of $X-c-C_{n} H_{2 n-1}(X=$ COOMe $)$ were bracketed between those of reference compounds $\mathrm{BH}$ (see Results section) by studying the (non)occurrence of the proton transfer from $X-c-C_{n} H_{2 n-1}$ to $B^{-}$.

The temperature $\mathrm{T}$ (see eq 1) of the reaction mixture in the FT-ICR cell was estimated to be about $330 \mathrm{~K}$, which is in between the temperature of the vacuum system $(298 \mathrm{~K})$ and the temperature of the trapping plate $(350 \mathrm{~K})$ opposite to the filament as measured by a thermocouple.

\section{Materials}

All studied cyanocycloalkanes, phenylcyclopropane, phenylcyclohexane, nitrocyclopentane, nitrocyclohexane, and all reference compounds used (see Results section) were commercially available. Phenylcyclobutane, -pentane, and -heptane were prepared by Grignard synthesis with bromobenzene and $\mathrm{RMgBr}$. The methoxycarbonylcycloalkanes were prepared by esterification of the corresponding acids by the use of diazomethane [28]. Nitrocyclo-propane [29], -butane [30], and -heptane were synthesized according to literature procedures. All synthesized compounds were identified by infrared, NMR, and mass spectrometry. The studied compounds were purified by preparative gas chromatography (columns: OV-1 and Reoplex) before use.

\section{Results}

\section{Phenylcycloalkanes}

Gas-phase acidities of phenylcycloalkanes, Ph-c$\mathrm{C}_{\mathrm{n}} \mathrm{H}_{2 \mathrm{n}-1}$, have been determined relative to reference compounds $\mathrm{BH}$ by equilibrium constant measurements associated with the reversible proton transfer reactions of the general type shown in eq 3 (see Experimental section):

$$
\mathrm{B}^{-}+c-\mathrm{C}_{\mathrm{n}} \mathrm{H}_{2 \mathrm{n}-1} \mathrm{X} \underset{\mathrm{k}_{-1}}{\stackrel{\mathbf{k}_{1}}{\rightleftharpoons}} \mathrm{BH}+c-\mathrm{C}_{\mathrm{n}} \mathrm{H}_{2 \mathrm{n}-2} \mathrm{X}^{-}
$$

It is found that methanol $\left(\Delta G_{\text {acid }}^{\mathrm{a}}=1565 \mathrm{~kJ} \mathrm{~mol}^{-1}\right)$ [31] is 4,5 , and $1 \mathrm{~kJ} \mathrm{~mol}^{-1}$ less acidic than phenylcycloprupante, phenylcyclohexane, and phenylcycloheptane, respectively, while ethanol $\left(\Delta \mathrm{G}_{\text {acid }}^{\mathrm{a}}=1551 \mathrm{~kJ} \mathrm{~mol}^{-1}\right)$ [31] is found to be 1 and $3 \mathrm{~kJ} \mathrm{~mol}^{-1}$ less acidic than phenylcyclobutane and phenylcyclopentane, respectively (see acidity scale in Figure 1).

Strikingly, the present proton transfer equilibrium measurements indicate that phenylcyclopropane 


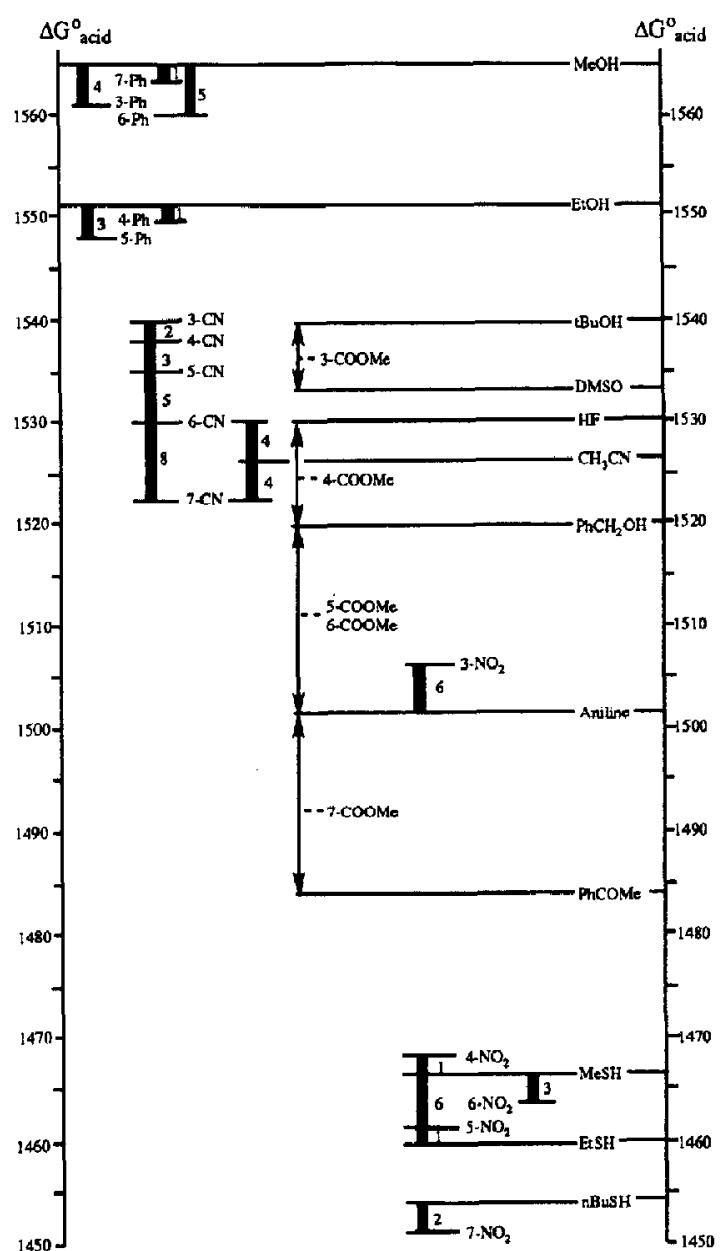

Figure 1. Acidity scale (values in $\mathrm{kJ} \mathrm{mol}^{-1}$ ). $\mathrm{n}-\mathrm{X}$ refers to $X-c-C_{n} H_{2 n-1}$. refers to $\Delta G^{c}{ }_{\text {acid }}(B H)-\Delta G^{o}{ }_{\text {acid }}(A H)$ from equilibrium measurements associated with $\mathrm{A}^{-}+\mathrm{BH} \rightleftharpoons \mathrm{AH}+\mathrm{B}^{-}$. $\downarrow$ refers to $\Delta G^{0}{ }_{\text {acid }}\left(B_{1} H\right)>\Delta G_{\text {acid }}^{0}(A H)>\Delta G^{0}{ }_{\text {acid }}\left(B_{2} H\right)$ from bracketing measurements associated with the (non)occurrence of $\mathrm{B}^{-}+\mathrm{AH} \rightarrow \mathrm{BH}+\mathrm{A}^{-}$.

$\left(\Delta \mathrm{C}^{\circ}{ }_{\text {acid }^{-}} 1561 \mathrm{~kJ} \mathrm{~mol}{ }^{-1}\right.$ ) is about $46 \mathrm{~kJ} \mathrm{~mol}^{-1}$ more acidic than suggested by two previous independent studies [22, 32] where PA bracketing of deprotonated phenylcyclopropane, generated by deprotonation of the parent neutral molecule by $\mathrm{OH}^{-}$under FA conditions, indicated that the acidity of phenylcyclopropane is very close to the acidity of water $\left(\Delta \mathrm{G}^{\circ}{ }_{\text {acid }}=1607\right.$ kJ $\mathrm{mol}^{-1}$ ).

Both FA studies $[22,32]$ showed that under the conditions deprotonated phenylcyclopropane exchanges at least five of its hydrogens by deuterium in an atmosphere of $\mathrm{D}_{2} \mathrm{O}$, which clearly indicates that the aryl hydrogens are involved in the deprotonation.

This result is reproduced under the present relatively low pressure FT-ICR conditions. In addition it is found that upon deprotonation of phenylcyclopropane by $\mathrm{OH}^{-}$, the total population of the resulting deprotonated phenylcyclopropanes abstracts very rapidly a proton from methanol. Subsequently, the resulting $\mathrm{CH}_{3} \mathrm{O}^{-}$ions extremely slowly react with phenylcyclopropane to regenerate the deprotonated phenylcyclopropane. The latter reaction leads to an equilibrium concentration of deprotonated phenylcyclopropane and $\mathrm{CH}_{3} \mathrm{O}^{-}$ions from which it follows that phenylcyclopropane is about $4 \mathrm{~kJ} \mathrm{~mol}^{-1}$ more acidic than methanol (see above). The above results can be rationalized with Scheme I.

Reaction between $\mathrm{OH}^{-}$and phenylcyclopropane $\mathbf{I}$ is considered to result in a rapid formation of the cyclopropyl substituted phenyl anion 2b. Although benzene itself is not acidic enough $\left(\Delta \mathrm{G}^{\circ}{ }_{\text {acid }}=1636 \mathrm{~kJ}\right.$ $\mathrm{mol}^{-1}$ ) [31] to become deprotonated by $\mathrm{OH}^{-}$, the cyclopropyl substituent may enhance the acidity of the aryl positions by about $30 \mathrm{~kJ} \mathrm{~mol}^{-1}$ to bring it close to water, as already has been demonstrated for the related vinyl substituent in styrene [33].

Although deprotonation of $\underline{1}$ by $\mathrm{OH}^{-}$at the cyclopropyl $C_{a}$ position yielding the phenylcyclopropyl carbanion $2 \mathrm{a}$ is expected to be favored energetically, this reaction is anticipated to be hampered by a large entropy barrier which is associated with the rehybridization around $\mathrm{C}_{\alpha}$ and with the rotation of the $\mathrm{C}_{\alpha}-\mathrm{Ph}$ bond to optimize resonance stabilization. This impediment is not an uncommon phenomenon in the formation of delocalized carbanions [34] and most likely is the reason why proton transfer reactions of the general type shown in eq 4 (below) have been found unsuccessful for the series of phenylcycloalkanes.

The cyclopropyl substituted phenyl anion $\mathbf{2 b}$, generated by $\mathrm{OH}^{-}$, rapidly can abstract a proton from methanol. However, the reaction of the resulting $\mathrm{CH}_{3} \mathrm{O}^{-}$with $\underline{\mathbf{1}}$ back to $\underline{2 b}$ is energetically blocked.

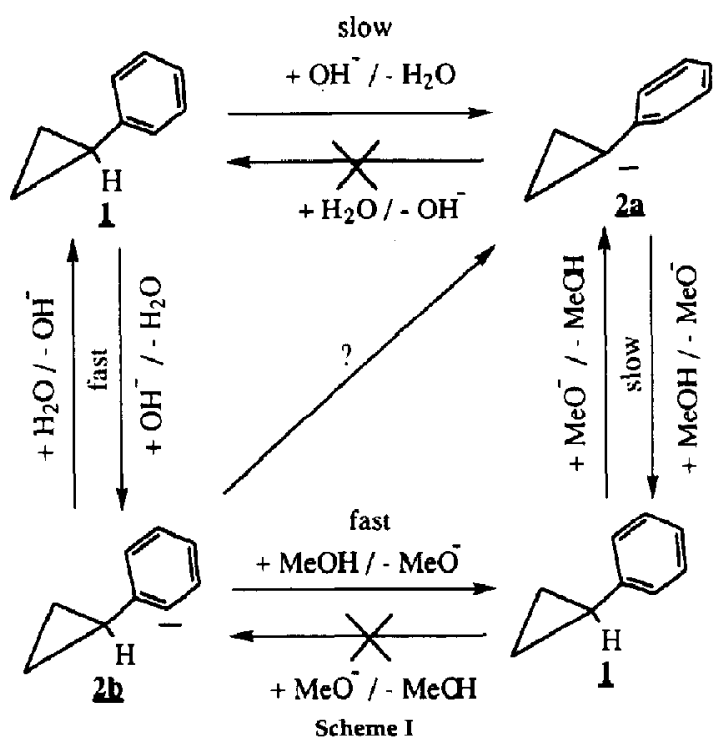


Instead, $\mathrm{CH}_{3} \mathrm{O}^{-}$induces a slow entropically hindered but energetically allowed proton abstraction resulting in formation of the phenylcyclopropyl carbanion 2a. Evidence for the formation of $2 \mathrm{a}$ is obtained from the observation that the deprotonated phenylcyclopropane generated in this way does not exchange hydrogens for deuterium in an atmosphere of $\mathrm{CH}_{3} \mathrm{OD} / \mathrm{D}_{2} \mathrm{O}$.

In conclusion, it appears that proton abstraction of phenylcyclopropane by $\mathrm{OH}^{-}$results in the formation of the cyclopropyl substituted phenyl anion $\mathbf{2 b}$ which only extremely slowly is converted to the more stable phenylcyclopropyl carbanion $\mathbf{2 a}$.

In view of this, it seems justifiable to reevaluate the results of the previous FA studies, which were set up to characterize the bimolecular reactivity of the phenylcyclopropyl carbanion 2a toward a series of substrate molecules in comparison with the ringopened 2- and 3-phenylallyl anion isomers [22,32] and to analyze the barrier of $2 \mathrm{a}$ toward thermally induced ring opening $[22,35]$.

\section{Cyanocycloalkanes}

In contrast to the above phenylcycloalkanes, reversible proton transfers of the general type shown in eq 4

$$
\begin{gathered}
c-C_{n} H_{2 n-2} X^{-}+c-C_{n+1} H_{2 n+1} X \frac{k_{1}}{k_{1}} \\
c-C_{n} H_{2 n-1} X+c-C_{n+1} H_{2 n} X^{-}
\end{gathered}
$$

are sufficiently fast in the series of cyanosycloalkanes, $\mathrm{NC}-c-\mathrm{C}_{\mathrm{n}} \mathrm{H}_{2 \mathrm{n}-1}$, to allow equilibration under the applied conditions. Apparently, resonance charge delocalization effected by the cyano group is of less importance than for the phenyl group (see also Discussion section) as a consequence of which proton transfer is less hindered by a substantial activation entropy. The above observed reversible proton transfer reactions allowed relative acidity measurements within the serics of cyanocycloalkanes. Within this series cyanocyclopropane, which has been shown earlier [36] to be deprotonated exclusively at the substituted carbon atom, is the least acidic. Cyanocyclobutane is found to be $2 \mathrm{~kJ} \mathrm{~mol}{ }^{-1}$ more acidic than cyanocyclopropane, cyanocyclopentane $3 \mathrm{~kJ} \mathrm{~mol}^{-1}$ more acidic than cyanocyclobutane, cyanocyclohexane $5 \mathrm{~kJ} \mathrm{~mol}^{-1}$ more acidic than cyanocyclopentane, and finally, cyanocycloheptane $8 \mathrm{~kJ} \mathrm{~mol}^{-1}$ more acidic than cyanocyclohexane. Anchoring of these relative acidities to the absolute acidity scale has been realized by determining the acidities of cyanocyclohexane and cyanocycloheplane relative to the reference acid acetonitrile $\left(\Delta G^{\circ}\right.$ acia $=1528 \mathrm{~kJ} \mathrm{~mol}^{-1}$ ) [31, 37]. The results show that acetonitrile is $4 \mathrm{~kJ} \mathrm{~mol}^{-1}$ more acidic than cyanocyclohexane and $4 \mathrm{~kJ} \mathrm{~mol}^{-1}$ less acidic than cyanocycloheptane, in perfect agreement with the above found $8 \mathrm{~kJ} \mathrm{~mol}^{-1}$ acidity difference between cyanocyclohexane and cyanocycloheptane.
From the anchoring of the acidities of the series of cyanocycloalkanes (see acidity scale in Figure 1), it follows that the acidity of cyanocyclopropane becomles $1540 \mathrm{~kJ} \mathrm{~mol}^{-1}$, in perfect agreement with the literature value [31].

Evidence that the generated deprotonated cyanocycloalkanes have a cycloalkyl carbanion structure has been obtained from the observation that no deuterium is incorporated in an atmosphere of $\mathrm{CH}_{3} \mathrm{OD}$ or $\mathrm{C}_{2} \mathrm{H}_{5} \mathrm{OD}$.

\section{Methoxycarbonylcycloalkanes}

Unfortunately, proton transfer equilibrium constant measurements involving methoxycarbonylcycloalkanes, MeOOC- $c-C_{n} H_{2 n-1}$ are obscured by side reactions, where reference bases, $\mathrm{B}^{-}$, react as nucleophiles, causing substitution on both the carbonyl and the methyl carbon [38]. Alternatively, the acidities of the methoxycarbonylcycloalkanes have been bracketed between those of reference compounds $\mathrm{BH}$ (see acidity scale in Figure 1) by studying the (non)occurrence of the proton Iransfer from MeOOC-c- $\mathrm{I}_{2 \mathrm{n}-1}$ to $\mathrm{B}^{-}$.

Following this procedure the acidity of methoxycarbonylcyclopropane is bracketed between those of tBuOH $\left(\Delta \mathrm{G}^{\circ}{ }_{\text {acid }}-1540 \mathrm{~kJ} \mathrm{mul}^{-1}\right)$ [31] and DMSO $\left(\Delta \mathrm{G}_{\text {acid }}^{\circ}=1533 \mathrm{~kJ} \mathrm{~mol}^{-1}\right)$ [31], of methoxycarbonylcyclobutane between those of $\mathrm{HF}\left(\Delta \mathrm{G}^{\circ}{ }_{\text {acid }}=1530 \mathrm{~kJ}\right.$ $\left.\mathrm{mol}^{-1}\right)$ [31] and $\mathrm{PhCH}_{2} \mathrm{OH}\left(\Delta \mathrm{G}^{\circ}{ }_{\text {acid }}=1520 \mathrm{~kJ} \mathrm{~mol}^{1}\right)$ [31], of methoxycarbonylcyclopentane and methoxycarbonylcyclohexane between those of $\mathrm{PhCH}_{2} \mathrm{OH}$ $\left(\Delta \mathrm{G}^{\circ}{ }_{\text {acid }}=1520 \mathrm{~kJ} \mathrm{~mol}^{1}\right)$ [31] and aniline $\left(\Delta \mathrm{G}^{\circ}{ }_{\text {acid }}=\right.$ $1502 \mathrm{~kJ} \mathrm{~mol}^{-1}$ ) [31], and of methoxycarbonylheptane between those of aniline $\left(\Delta \mathrm{G}^{\circ}{ }_{\text {acid }}=1502 \mathrm{~kJ} \mathrm{~mol}^{-1}\right)$ [31] and thCOMe $\left(\Delta G^{\circ}{ }_{\text {acid }}=1484 \mathrm{~kJ} \mathrm{~mol}^{1}\right)$ [31].

Evidence that the generated deprotonated methoxycarbonylcycloalkanes have a cycloalkyl carbanion structure has been obtained from the observation that no deuterium is incorporated in an atmosphere of $\mathrm{CH}_{3} \mathrm{OD}$ or $\mathrm{C}_{2} \mathrm{H}_{5} \mathrm{OD}$.

\section{Nitrocycloalkanes}

As for the phenylcycloalkanes, proton transfers of the general type shown by eq 4 have been found to be unsuccessful for any of the nitrocycloalkane pairs. $\Lambda \mathrm{p}$ parently, resonance charge delocalization in the corresponding carbanions effected by the nitro group is of more importance than for the cyano group (see above), resulting in a substantial activation entropy associated with the proton transfers.

Alternatively, reversible proton transfers have been observed of the general type shown in eq 3 by using acids, $\mathrm{HB}$, with conjugated anionic, more charge localized, hetero bases, $\mathrm{B}^{-}$.

The equilibrium constant measurements show that aniline $\left(\Delta G_{\text {acid }}^{\circ}=1502 \mathrm{~kJ} \mathrm{~mol}^{-1}\right)$ [31] is $6 \mathrm{~kJ} \mathrm{~mol}^{-1}$ more acidic than nitrocyclopropane, $\mathrm{MeSH}\left(\Delta \mathrm{G}^{\circ}{ }_{\text {acid }}=\right.$ 
$1467 \mathrm{~mol}^{-1}$ ) [31] is $1 \mathrm{~kJ} \mathrm{~mol}^{-1}$ more acidic than nitrocyclobutane and 6 and $3 \mathrm{~kJ} \mathrm{~mol}^{-1}$ less acidic than nitrocyclopentane and nitrocyclohexane, respectively. In agreement, EtSH ( $\left.\Delta \mathrm{G}^{\circ}{ }_{\text {acid }}=1460 \mathrm{~kJ} \mathrm{~mol}^{-1}\right)$ [31] is 1

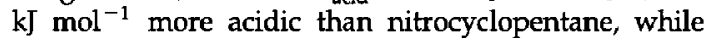
$\mathrm{nBuSH}\left(\Delta \mathrm{G}^{\mathrm{o}}{ }_{\text {acid }}=1454 \mathrm{~kJ} \mathrm{~mol}^{-1}\right)$ [31] is $2 \mathrm{~kJ} \mathrm{~mol}^{-1}$ less acidic that nitrocycloheptane (see acidity scale in Figure 1).

From the results, it appears that the presently determined acidity of nitrocyclopropane, which has been shown earlier [36] to be deprotonated exclusively at the substituted carbon atom is in perfect agreement with a recently reported experimental value [21] of $1509 \mathrm{~kJ} \mathrm{~mol}^{-1}$. Evidence that the generated deprotonated nitrocycloalkanes have a cycloalkyl carbanion structure has been obtained from the observation that no deuterium is incorporated in an atmosphere of $\mathrm{CH}_{3} \mathrm{CH}_{2} \mathrm{CH}(\mathrm{OD}) \mathrm{CH}_{3}$ or $\mathrm{CF}_{3} \mathrm{CH}_{2} \mathrm{OD}$.

\section{Determination of the Substituent Carbanion Stabilization Energy}

To nbtain a consistent scale of gas-phase acidities at $298 \mathrm{~K}$, rather than at $330 \mathrm{~K}$, which is the estimated temperature, $T$, of the studied equilibrium reaction mixtures (see Experimental section), the relative acidities obtained must be corrected for the entropy change for every proton transfer equilibrium reaction according to eq 5 :

$$
\begin{aligned}
\delta \Delta G_{\text {acid }}^{0}(298 \mathrm{~K})= & \delta \Delta \mathrm{G}^{\mathrm{o}}{ }_{\text {acid }}(\mathrm{T}) \\
& +\delta \Delta \mathrm{S}_{\text {acid }}^{\mathrm{a}}(\mathrm{T}-298 \mathrm{~K})
\end{aligned}
$$

However, since $\delta \Delta \mathrm{S}^{\circ}{ }_{\text {acid }}$ can be estimated [39] to be maximally $20 \mathrm{~J} \mathrm{~mol}^{-1} \mathrm{~K}^{-1}$, the magnitude of these corrections is maximally $0.6 \mathrm{~kJ} \mathrm{~mol}^{-1}$, which seems to be within the error of the relative acidity measurements and therefore corrections are disregarded in this study.

The experimentally obtained gas-phase acidities of the substituted cycloalkanes are transformed to PA of the corresponding substituted cycloalkyl carbanions according to:

$$
\begin{aligned}
\operatorname{PA}\left(X-c-C_{n} H_{2 n-2}{ }^{-}\right)= & \Delta H^{o}{ }_{\text {acid }}\left(X-c-C_{n} H_{2 n-1}\right) \\
= & \Delta G^{o}{ }_{a c i d}\left(X-c-C_{n} H_{2 n-1}\right) \\
& +T \Delta S^{o}{ }_{\text {acid }}\left(X-c-C_{n} H_{2 n-1}\right)
\end{aligned}
$$

The $\Delta S^{o}{ }_{\text {acid }}\left(X-c-C_{n} H_{2 n-1}\right)$ values used (see Table 1) are approximated by the values for the corresponding $X$ substituted secondary carbon acids as obtained by Bartmess et al. [39] by using a statistical mechanic method. The errors in $\Delta \mathrm{S}^{\circ}{ }_{\text {acid }}\left(\mathrm{X}-\mathrm{c}-\mathrm{C}_{\mathrm{n}} \mathrm{H}_{2 \mathrm{n}-1}\right)$ are estimated to be maximally $8 \mathrm{~J} \mathrm{~mol}^{-1} \mathrm{~K}^{-1}$, which corresponds to a maximum error of about $2 \mathrm{~kJ} \mathrm{~mol}^{-1}$ in the $\mathrm{T} \Delta \mathrm{S}^{\circ}{ }_{\text {acid }}\left(\mathrm{X}-\mathrm{c}-\mathrm{C}_{\mathrm{n}} \mathrm{H}_{2 \mathrm{n}-1}\right)$ term. The obtained $\Delta \mathrm{H}^{\mathrm{o}}$ acid $\left(X-c-C_{n} H_{2 n-1}\right), P A\left(X-c-C_{n} H_{2 n-2}{ }^{-}\right)$values are listed in Table 1.

\begin{tabular}{|c|c|c|c|c|}
\hline$X-c-C_{n} H_{2 n-1}$ & $\begin{array}{c}\Delta S^{0}{ }_{\text {acid }}^{\mathrm{o}} \\
\left(J \mathrm{~mol}^{-1} \mathrm{~K}^{-1}\right)\end{array}$ & $\begin{array}{c}\Delta G^{0}{ }_{\text {acid }}^{-{ }^{\prime}} \\
\left(k . J \mathrm{~mol}^{-1}\right)\end{array}$ &  & $\begin{array}{c}\Delta H^{\circ}{ }_{\text {stab }}^{b} \\
\left.(\mathrm{~kJ} \mathrm{~mol})^{-1}\right)\end{array}$ \\
\hline $\mathrm{Ph}-c-\mathrm{C}_{3} \mathrm{H}_{5}$ & 85 & 1561 & 1586 & 122 \\
\hline $\mathrm{Ph}-c-\mathrm{C}_{4} \mathrm{H}_{7}$ & 85 & 1550 & 1575 & 182 \\
\hline $\mathrm{Ph}-c-\mathrm{C}_{5} \mathrm{H}_{\mathrm{g}}$ & 85 & 1548 & 1574 & 176 \\
\hline $\mathrm{Ph}-c-\mathrm{C}_{6} \mathrm{H}_{11}$ & 85 & 1560 & 1585 & 165 \\
\hline $\mathrm{Ph}-c-\mathrm{C}_{7} \mathrm{H}_{13}$ & 85 & 1564 & 1590 & 149 \\
\hline$N C-c-C_{3} H_{5}$ & 106 & 1540 & 1571 & 137 \\
\hline $\mathrm{NC}-c-\mathrm{C}_{4} \mathrm{H}_{7}$ & 101 & 1538 & 1568 & 189 \\
\hline $\mathrm{NC}-c-\mathrm{C}_{5} \mathrm{H}_{9}$ & 101 & 1535 & 1565 & 185 \\
\hline$N C-c-C_{6} H_{11}$ & 101 & 1530 & 1560 & 190 \\
\hline $\mathrm{NC}-\mathrm{c}-\mathrm{C}_{7} \mathrm{H}_{13}$ & 101 & 1522 & 1552 & 187 \\
\hline $\mathrm{MeOOC}-c-\mathrm{C}_{3} \mathrm{H}_{5}$ & 95 & 1536 & 1565 & 143 \\
\hline $\mathrm{MeOOC}-c-\mathrm{C}_{4} \mathrm{H}_{7}$ & 95 & 1525 & 1554 & 203 \\
\hline $\mathrm{MeOOC}-c-\mathrm{C}_{5} \mathrm{H}_{9}$ & 95 & 1512 & 1541 & 209 \\
\hline $\mathrm{MeOOC}-c-\mathrm{C}_{6} \mathrm{H}_{11}$ & 95 & 1512 & 1541 & 209 \\
\hline $\mathrm{MeOOC}-c-\mathrm{C}_{7} \mathrm{H}_{13}$ & 95 & 1492 & 1521 & 218 \\
\hline $\mathrm{O}_{2} \mathrm{~N}-\mathrm{C}-\mathrm{C}_{3} \mathrm{H}_{5}$ & 85 & 1508 & 1534 & 174 \\
\hline $\mathrm{O}_{2} \mathrm{~N}-c-\mathrm{C}_{4} \mathrm{H}_{7}$ & 85 & 1468 & 1493 & 264 \\
\hline $\mathrm{O}_{2} \mathrm{~N}-c-\mathrm{C}_{5} \mathrm{H}_{9}^{\prime}$ & 85 & 1461 & 1487 & 263 \\
\hline $\mathrm{O}_{2} \mathrm{~N}-c-\mathrm{C}_{6} \mathrm{H}_{11}$ & 85 & 1464 & 1490 & 260 \\
\hline $\mathrm{O}_{2} \mathrm{~N}-6-\mathrm{C}_{7} \mathrm{H}_{13}$ & 85 & 1452 & 1478 & 261 \\
\hline
\end{tabular}

Substituent carbanion stabilization energies, $\Delta \mathbf{H}^{\mathrm{a}}{ }_{\text {stab}}$, have been determined as the negative enthalpy change in the isodesmic reactions described by

Table 1. Thermochemical Data for Some Substituted Cycloalkanes

avalues taken from ref 39 (see text).

${ }_{\Delta}^{b} H_{s t a b}\left(\right.$ exp) $=P A\left[H-c-C_{n} H_{2 n-2}\right]-P A\left[X-c-C_{n} H_{2 n-2}\right]$ (see text). 
eq $7(n=3,4,5,6,7)$ :

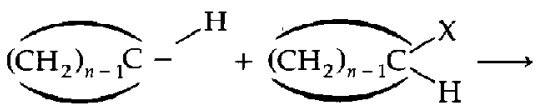

$$
\begin{aligned}
& (\overbrace{\left.\mathrm{CH}_{2}\right)_{n-1} \mathrm{C}}^{-H}+\overbrace{H}^{\left(\mathrm{CH}_{2}\right)_{n-1} \mathrm{C}}-{ }^{X} \\
& \Delta \mathrm{H}_{\text {stab }}^{\mathrm{o}}(\exp )=-\Delta \mathrm{H}_{(\text {reaction } 7)}^{\mathrm{o}}= \\
& \operatorname{PA}\left(\mathrm{H}-c-\mathrm{C}_{n} \mathrm{H}_{2 \mathrm{n}-\overline{2}}\right)-\mathrm{PA}\left(\mathrm{X}-c-\mathrm{C}_{\mathrm{n}} \mathrm{H}_{2 \mathrm{n}-\overline{2}}\right)
\end{aligned}
$$

PA(H-c- $\left.\mathrm{C}_{n} \mathrm{H}_{2 \mathrm{n}-2}\right)$ values are taken from our previous study [23] where the PAs of cyclopropyl, cyclobutyl cyclopentyl, cyclohexyl, and cycloheptyl carbarions were determined, by using an indirect desilylation method, to be $1708,1757,1750,1750$, and $1739 \mathrm{~kJ}$ $\mathrm{mol}^{-1}$, respectively. The determined stabilization energies, $\Delta \mathrm{H}^{\circ}{ }_{\text {stab }}$, for each of the studied substituted cyclopropyl carbanions are included in Table 1.

\section{Discussion}

The results in Table 1 show that the ability of the substituent to stabilize the cycloalkyl carbanions increases along the series $\mathrm{Ph}, \mathrm{CN}, \mathrm{COOMe}$, and $\mathrm{NO}_{2}$. As expected for all studied substituents, stabilization of the cyclopropyl carbanion is strikingly less efficient than for the larger cycloalkyl carbanions. This is illustrated in Figure 2, in which the stabilization energy is plotted against the cycloalkyl ring-size.

The dramatic reduction of the stabilization energy for the cyclopropyl carbanions is anticipated if it is considered that the rigid cyclopropyl group hinders

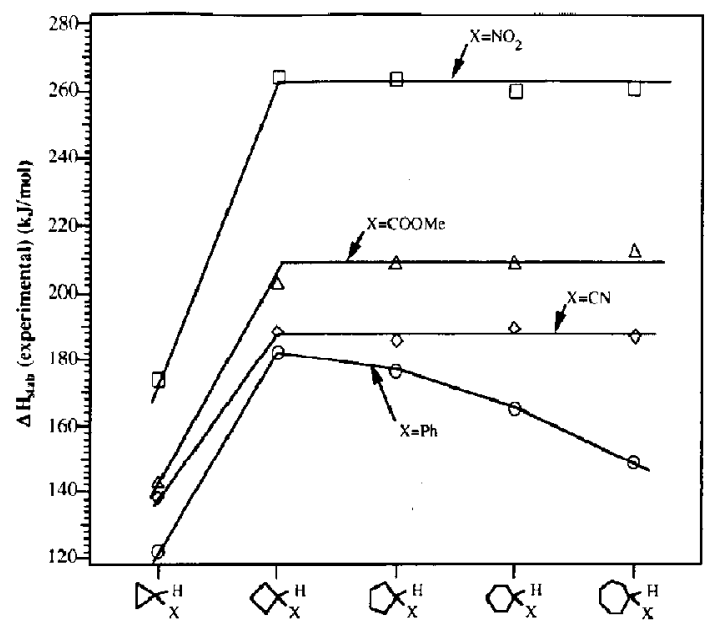

Figure 2. Substituent stabilization energy of cycloalkyl carbanions as a function of ring-size. rehybridization of the carbanion from a pyramidal to a planar $s p_{2}$ hybridization state which is required to maximize overlap of the carbanion HOMO with the $X$ $\pi^{*}$ orbital and hence optimize stabilization via resonance charge $\pi$-delocalization. However, the above rehybridization is in conflict with optimization of the stabilization via inductive charge $\sigma$-delocalization, which requires further pyramidalization of the carbanion to maximize overlap of the carbanion HOMO with the $\sigma^{*}(\mathrm{C}-\mathrm{X})$ orbital.

The tendency of $\alpha$-substituted carbanions to rehybridize is illustrated by Figure 3, which shows the most recently reported theoretical data $[18,22]$ on the out-of-plane angle $\alpha$ and corresponding inversion barrier of some substituted cyclopropyl carbanions. Clearly, pyramidalization occurs upon substitution of the cyclopropyl carbanion $(\mathrm{X}=\mathrm{H})$ with inductively stabilizing substituents such as $\mathrm{OH}, \mathrm{NH}_{2}$, and $\mathrm{F}$, which is accompanied by a dramatic increase of the carbanion inversion barrier.

Upon substitution with dominantly resonance stabilizing substituents, such as $\mathrm{CN}, \mathrm{CH}=\mathrm{CH}_{2}, \mathrm{NO}_{2}$, and $\mathrm{CHO}$, rehybridization occurs toward a more planar $\mathrm{sp}_{2}$ hybridization state, which is accompanied by a dramatic decrease of the carbanion inversion barrier (see Figure 3), suggesting that resonance stabilization gains importance along this series. In accordance, calculations show that substitution of the geometrically unrestricted methyl carbanions with $\mathrm{CHO}[2,3,5,9], \mathrm{NO}_{2}$ [11, 12], and $\mathrm{CH}=\mathrm{CH}_{2}$ [19] leads to a planar $\mathrm{sp}_{2}$ hybridization state, whereas $\mathrm{CN}$ [14] substituted



Figure 3. Out-of-plane angle versus carbanion inversion barrier for some substituted cyclopropyl carbanions. Theoretical data taken from ref 22, except for the data on the nitrocyclopropyl carbanion, which are taken from ref 18. 
methyl carbanions are still slightly nonplanar with an inversion barrier of a little over $1 \mathrm{~kJ} \mathrm{~mol}^{-1}$. The latter results on the $\mathrm{CH}_{2} \mathrm{CN}^{-}$ion has been reproduced by photoelectron spectroscopy [16].

Further, the increased s-character of the HOMO of the cyclopropyl carbanion and hence the lower HOMO energy (which is responsible for the decreased PA [23]) relative to the other cycloalkyl carbanions, may also influence the efficiency of the stabilizing substituent orbital interactions.

The results in Figure 2 clearly show that from cyclobutyl to cycloheptyl the $\mathrm{CN}, \mathrm{COOMe}$, and $\mathrm{NO}_{2}$ substituent stabilization energy is independent of the cycloalkyl ring-size, indicating that already the cyclobutyl group holds no geometric restriction with respect to optimization of the substituent carbanion stabilization.

However, stabilization of the cycloalkyl carbanions by $\mathrm{Ph}$ shows a different character. A maximum stabilization energy of $182 \mathrm{~kJ} \mathrm{~mol}^{-1}$ is found for the phenylcyclobutyl carbanion and this energy step-wise decreases down to $149 \mathrm{~kJ} \mathrm{~mol}^{-1}$ upon increasing the cycloalkyl ring-size. This behavior, shown in Figure 2, can be rationalized by assuming that resonance stabilization is restricted by the nonplanarity of the phenylcyclopropyl carbanion. The phenylcyclobutyl carbanion may have become planar, allowing optimal resonance stabilization. Increasing the alkyl ring-size enhances the steric hindrance between the phenyl ortho hydrogens and the $\beta$-cycloalkyl hydrogens. This hindrance causes a twist of the bond to the phenyl group, again resulting in a decrease of resonance stabilization. The assumed changes in carbanion geometry are shown qualitatively in Figure 4.

To gain insight, the experimental data of the substituent carbanion stabilization energies have been analyzed in terms of Taft's parametrization $[40,41]$ of polarizability (P), field/inductive $(\mathrm{F})$, and resonance (R) effects by using eq 9 .

$$
\Delta \mathrm{H}_{\text {stab }}^{\mathrm{i}}(\text { calc })=\overbrace{-\rho_{\alpha} \sigma_{\alpha}}^{\mathrm{P}}+\overbrace{\rho_{\mathrm{F}} \sigma_{\mathrm{F}}}^{\mathrm{F}}+\overbrace{\rho_{\mathrm{R}} \sigma_{\mathrm{R}}}^{\mathrm{R}}
$$

where $\rho_{\alpha}, \rho_{\mathrm{F}}, \rho_{\mathrm{R}}$ are the reaction constants and $\sigma_{\alpha \prime}$ $\sigma_{\mathrm{F}}, \sigma_{\mathrm{R}}$ are the substituent parameters, corresponding to $P, F$, and $R$ effects, respectively.

Generalized linear regression analyses of substituent effects have been successful for many gasphase proton transfer equilibrium reaction systems [40, 42, 43]. However, treatment of stabilization of simple $\alpha$-substituted carbanions has suffered from a limitation of available experimental data. It must be forewarned

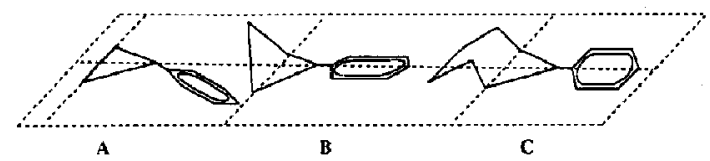

Figure 4. Qualitative geometry of the phenyl-cyclopropyl (A), -cyclobutyl (B), and -cycloheptyl (C) carbanion. that in comparison with anionic hetero bases, carbanions can experience large perturbations upon $\alpha$-substitution (see above). If these perturbations become too extreme, the required noncollinearity between the independent substituent parameters $\sigma_{\alpha}, \sigma_{\mathrm{F}}$, and $\sigma_{\mathrm{R}}$ may be lost [43].

Therefore, the applicability of eq 9 for carbanions has been tested for a series of methyl carbanions with primarily resonance (with a limited range of $\sigma_{\mathrm{R}}$ from 0.1 to 0.19 ) stabilizing substituents by fitting the three reaction constants $\rho_{\alpha}, \rho_{\mathrm{F}}$, and $\rho_{\mathrm{R}}$ of eq 9 to the stabilization energies. These stabilization energies have been determined as the negative enthalpy changes in the isodesmic reactions shown in eq 10.

$$
\begin{aligned}
& \mathrm{CH}_{3}^{-}+\mathrm{XCH}_{3} \rightarrow \mathrm{CH}_{4}+\mathrm{XCH}_{2}^{-} \\
& \Delta \mathrm{H}^{\mathrm{o}}{ }_{\text {stab }}(\exp )=-\Delta \mathrm{H}^{\mathrm{o}}(\text { reaction 10) } \\
& =\mathrm{PA}\left(\mathrm{CH}_{3}^{-}\right)-\mathrm{PA}\left(\mathrm{XCH}_{2}^{-}\right)
\end{aligned}
$$

$\mathrm{PA}\left(\mathrm{CH}_{3}^{-}\right)$and $\mathrm{PA}\left(\mathrm{XCH}_{2}^{-}\right)$in eq 11 are taken from the literature [31].

Figure 5 and Table 2 show the results of the analysis, from which it appears that for substituents $X$ with resonance parameters $\sigma_{R}$ ranging from 0.1 to 0.19 an excellent fit is obtained of the determined stabilization energy data $\left(\Delta \mathrm{H}^{\circ}{ }_{\text {stab }}(\exp )\right)$ to eq $9\left(\Delta \mathrm{H}^{\circ}{ }_{\text {stab }}(\mathrm{calc})\right)$ with $\rho_{\alpha}, \rho_{\mathrm{F}}$, and $\rho_{\mathrm{R}}$, being 58, 140, and $770 \mathrm{~kJ} \mathrm{~mol}^{-1}$, respectively. It must be noted that the controversial [43] $\sigma_{\mathrm{R}}$ literature value of 0.22 for $\mathrm{Ph}$ strongly overestimated the resonance stabilization of the methyl carbanion by the phenyl group. Therefore, a value of 0.12 is adopted, which satisfies perfectly the correlations of all three analyzed carbanion series (see Table 2).

Encouraged by the above successful correlation, similar analyses have been undertaken for the studied substituted cyclopropyl, $\mathrm{X}-\mathrm{c}-\mathrm{C}_{3} \mathrm{H}_{4}{ }_{4}$, and the geometrically unrestricted larger cycloalkyl carbanions, $\mathrm{X}-c-$ $\mathrm{C}_{n} \mathrm{H}_{2 n-2}(\mathrm{n}=4,5,6,7)$.

Because no appreciable variation has been found for the substituent stabilization energies of the larger $\mathrm{cy}$ cloalkyl carbanions as a function of ring-size, $n$, for $\mathrm{X}=\mathrm{CN}, \mathrm{COOMe}$, and $\mathrm{NO}_{2}$, the stabilization energies for $\mathrm{X}-c-\mathrm{C}_{\mathrm{n}} \mathrm{H}_{2 \mathrm{n}-2}-(\mathrm{n}=4,5,6,7)$ are taken as the averages of the energies obtained for the cyclobutyl up to the cycloheptyl carbanions for each series (see Figure 2 and Table 2). However, to circumvent the effect of steric hindrance in the stabilization of $\mathrm{Ph}-c-\mathrm{C}_{\mathrm{n}} \mathrm{H}_{2 \mathrm{n}-2}-$ (sce above), the stabilization energy value for $\mathrm{Ph}-\mathrm{c}$ $\mathrm{C}_{\mathrm{n}} \mathrm{H}_{2 \mathrm{n}-2}$, used in the linear regression analysis, is taken to be that of the phenylcyclobutyl carbanion (see Figure 2 and Table 2).

The results of the linear regression analyses using eq 9 for the substituted cycloalkyl carbanions are in cluded in Table 2 and Figure 5. As for the substituted methyl carbanions, $\mathrm{XCH}_{2}^{-}$, the results for both $\mathrm{X}-\mathrm{c}-$ $\mathrm{C}_{3} \mathrm{H}_{4}{ }^{-}$and $\mathrm{X}-\mathrm{c}-\mathrm{C}_{\mathrm{n}} \mathrm{H}_{2 \mathrm{n}-2}{ }^{-}(\mathrm{n}=4,5,6,7)$ series show that an excellent fit is obtained of the experimental stabilization energy data $\left(\Delta \mathrm{H}^{\circ}{ }_{\text {stab }}(\exp )\right)$ to eq 9 
Table 2. Analysis of carbanion stabilization energy, $\Delta \mathrm{H}_{\text {stab }}$, by equation 9

\begin{tabular}{|c|c|c|c|c|c|c|c|c|c|c|c|c|}
\hline $\mathrm{X}-\mathrm{R}$ & $\dot{\rho}_{\mathbf{a}}{ }^{a}$ & $\rho_{\mathrm{F}}^{\mathrm{a}}$ & $\mu_{R}^{a}$ & $x$ & $v_{a x}{ }^{b}$ & $u_{F}^{b}$ & $u_{R}^{b}$ & $P^{c, d}$ & $F^{c, d}$ & $R^{\mathbf{c} \cdot d}$ & $\begin{array}{l}\Delta H_{\text {stab }} \\
(\text { calc })^{\mathrm{d}}\end{array}$ & $\begin{array}{c}\Delta H_{\text {stab }} \\
(\exp )^{d, a} \\
\end{array}$ \\
\hline \multirow[t]{8}{*}{$\overline{\mathrm{X}-\mathrm{CH}_{2}^{-}}$} & 58 & 140 & 770 & $\overline{P h}$ & -0.81 & 0.10 & $(0.12)^{4}$ & 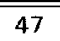 & $\bar{~} 14$ & 92 &  & $152^{9}$ \\
\hline & & & & $\mathrm{CONMe}_{2}$ & -0.66 & 0.19 & 0.14 & 38 & 27 & 108 & 173 & $175^{9}$ \\
\hline & & & & CN & -0.46 & 0.60 & 0.10 & 21 & 84 & 17 & 188 & $186^{9}$ \\
\hline & & & & $\mathrm{CO}_{2} \mathrm{Me}$ & -0.49 & 0.24 & 0.16 & 28 & 34 & 123 & 185 & $188^{9}$ \\
\hline & & & & COMe & -0.55 & 0.26 & 0.17 & 32 & 36 & 131 & 199 & $200^{9}$ \\
\hline & & & & $\mathrm{SO}_{2} \mathrm{Me}$ & -0.62 & 0.59 & 0.12 & 36 & 83 & 92 & 211 & $213^{g}$ \\
\hline & & & & $\mathrm{COH}$ & -0.46 & 0.31 & 0.19 & 27 & 43 & 146 & 216 & $216^{\mathrm{g}}$ \\
\hline & & & & $\mathrm{NO}_{2}$ & -0.26 & 0.65 & 0.18 & 15 & 92 & 139 & 246 & $249^{9}$ \\
\hline \multirow{4}{*}{$\begin{array}{l}X-c-C_{n} H_{2 n-2} \\
(n=4,5,6,7)\end{array}$} & 58 & 105 & 985 & $\mathrm{Ph}$ & -0.81 & 0.10 & $(0.12)^{f}$ & 47 & 12 & 118 & 177 & 182 \\
\hline & & & & $\mathrm{CN}$ & -0.46 & 0.60 & 0.10 & 27 & 63 & 99 & 189 & 188 \\
\hline & & & & $\mathrm{CO}_{2} \mathrm{Me}$ & -0.49 & 0.24 & 0.16 & 28 & 25 & 158 & 211 & 210 \\
\hline & & & & $\mathrm{NO}_{2}$ & -0.26 & 0.65 & 0.18 & 15 & 68 & 177 & 260 & 262 \\
\hline \multirow[t]{4}{*}{$\mathrm{X}-c-\mathrm{C}_{3} \mathrm{H}_{4}$} & 58 & 90 & 570 & $\mathrm{Ph}$ & -0.81 & 0.70 & $(0.12)^{f}$ & 47 & 9 & 68 & 124 & 122 \\
\hline & & & & CN & -0.46 & 0.60 & 0.10 & 27 & 54 & 57 & 138 & 137 \\
\hline & & & & $\mathrm{CO}_{2} \mathrm{Me}$ & -0.49 & 0.24 & 0.16 & 28 & 22 & 92 & 142 & 143 \\
\hline & & & & $\mathrm{NO}_{2}$ & -0.26 & 0.65 & 0.18 & 15 & 59 & 102 & 176 & 174 \\
\hline
\end{tabular}

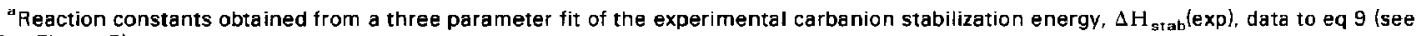
also Figure 5).

${ }^{b}$ Substituent parameters taken from ref 43

Individual contributions to $\Delta \mathrm{H}_{\mathrm{stab}}$ (calc) from polarizability, $\mathrm{P}=\rho_{\alpha} * \sigma_{\alpha}$, field /inductive, $\mathrm{F}=\rho_{\mathrm{F}} * \sigma_{\mathrm{F}}$, and resonance, $\mathrm{R}=\rho_{\mathrm{R}} * \sigma_{\mathrm{R}}$, effects

'In kJ mol'?

${ }^{0} \Delta \mathrm{H}_{\mathrm{stab}}(\mathrm{exp})=\mathrm{PA}\left[\mathrm{H}-\mathrm{R}^{-}\right]-\mathrm{PA}\left[\mathrm{X}-\mathrm{R}^{-}\right]$(see text).

'Because the controversial literature value of 0.22 appears to overestimate strongly the resonance stabilization of carbanions by $\mathrm{Ph}$, a value of 0.12 is adopted, which satisfies the correlation in all above series of carbanions (see text).

getermined by using the PA data from ref 31 (see under el.

$\left(\Delta \mathrm{H}_{\text {stab }}^{\mathrm{s}}(\mathrm{calc})\right)$. The above excellent correlations seem to allow, at least qualitatively, evaluation of the substituent effects.

Interestingly, the linear regression analyses show that the reaction constant, $\rho_{\alpha}$ is identical ( $58 \mathrm{~kJ} \mathrm{~mol}^{-1}$, see Table 2) for all three types of $\alpha$-substituted carbanions. This implies that the contribution of polarizability effects, P, to the overall carbanion stabilization energy



Figure 5. Independent fits of the substituent stabilization energy to eq 9 for the $X_{-}-\mathrm{CH}_{2}^{-}(O), X-c-\mathrm{C}_{n} \mathrm{H}_{2 n-2}(\mathrm{O})$, and $\mathrm{X}-c_{-}$ $\mathrm{C}_{3} \mathrm{H}_{4} \quad$ (a) carbanion series. is independent of the type of carbanion and only determined by the nature $\left(\sigma_{\alpha}\right)$ of the substituent.

However, the analyses suggest that the contribution of inductive effects, $\mathrm{F}$, is not only depending on the nature $\left(\sigma_{\mathrm{F}}\right)$ of the substituent, but also on the type of carbanion, as revealed by the decrease in the reaction constant, $\rho_{\mathrm{F}}$, from $140 \mathrm{~kJ} \mathrm{~mol}{ }^{-1}$ for $\mathrm{X}-\mathrm{CH}_{2}^{-}$, to $105 \mathrm{~kJ}$ mol ${ }^{1}$ for $X-c-C_{n} H_{2 n-2}$ to $90 \mathrm{~kJ} \mathrm{~mol}{ }^{1}$ for $X-c-C_{3} H_{4}{ }^{-}$ (see Table 2). This result suggests that substituent inductive stabilization is counteracted by the electron releasing effect of the alkyl groups.

Finally, it appears that the contribution of resonance effects, $R$, is very critical with respect to the nature of the substituted $\alpha$-carbanion. The significant gain in importance of resonance charge $\pi$-delocalization in going from the $X_{C H}^{-}$to the $X-c-C_{n} H_{2 n-2}(n=4,5,6,7)$ series, as exemplified by the reaction constants, $\rho_{\mathrm{R}}$, of 770 and $985 \mathrm{~kJ} \mathrm{~mol}^{-1}$, respectively, clearly reveals that in contrast to inductive stabilization, resonance stabilization is assisted by the electron releasing effect of the alkyl groups.

Dramatic reduction of resonance stabilization for the substituted cyclopropyl carbanion series, X-c$\mathrm{C}_{3} \mathrm{H}_{4}{ }^{-}$, due to a hindered rehybridization in the strained carbanions, is demonstrated by the relatively small reaction constant, $\rho_{\mathrm{R}}$, of $570 \mathrm{~kJ} \mathrm{~mol}^{-1}$.

\section{Conclusions}

For convenience, the data in Table 2 on the contributions of polarizability, inductive and resonance effects to the substituent stabilization energy for the $\mathrm{XCH}_{2}^{-}$, 


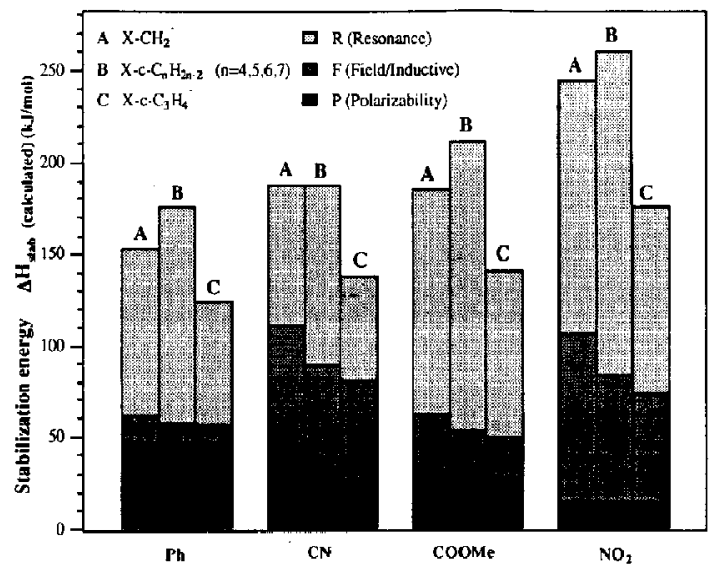

Figure 6. Contribution of polarizability, field/inductive, and resonance effects to the substituent stabilization energy of carbanions.

$\mathrm{X}-\mathrm{c}-\mathrm{C}_{\mathrm{n}} \mathrm{H}_{2 \mathrm{n}-2}{ }^{-}(\mathrm{n}=4,5,6,7)$, and $\mathrm{X}-\mathrm{c}-\mathrm{C}_{3} \mathrm{H}_{4}{ }^{-}$carbanion series with $X=\mathrm{Ph}, \mathrm{CN}, \mathrm{COOMe}$, and $\mathrm{NO}_{2}$ are displayed graphically in Figure 6, which shows that the contributions of polarizability effects are independent of the type of carbanions (A, B, and C).

Further, it appears that substituent stabilization is more effective in the substituted secondary, $\mathrm{X}-c$ $\mathrm{C}_{\mathrm{n}} \mathrm{H}_{2 n-\overline{2}}(\mathrm{n}=4,5,6,7)$, than in the corresponding substituted methyl, $\mathrm{XCH}_{2}^{\prime \prime}$, carbanions for $\mathrm{X}=\mathrm{Ph}$, $\mathrm{COOMe}$, and $\mathrm{NO}_{2}$. The enhanced substituent stabilization in the secondary $X_{-c}-C_{n} H_{2 n-2}(n=4,5,6,7)$ carbanions is the result of an increase of the contribution of resonance stabilization which is not completely canceled by a decrease of the contribution of inductive stabilization. Since the contributions of resonance and inductive stabilizations are more balanced for the cyano substituent, the increase of resonance stabilization is fully canceled by the decrease of inductive stabilization, as a result of which stabilization of the $\mathrm{CH}_{2} \mathrm{CN}^{-}$ and $c-\mathrm{C}_{\mathrm{n}} \mathrm{H}_{2 \mathrm{n}-2} \mathrm{CN}^{-}(\mathrm{n}=4,5,6,7)$ carbanions is equally effective (see Figure 6). Finally, it appears that substituent stabilization in the geometrically restricted substituted cyclopropyl carbanions, $\mathrm{X}-c-\mathrm{C}_{3} \mathrm{H}_{4}{ }^{-}$, is dramatically less effective than in the corresponding geometrically unrestricted larger substituted cycloalkyl carbanions, $\mathrm{X}-\mathrm{c}-\mathrm{C}_{\mathrm{n}} \mathrm{H}_{2 \mathrm{n}-2}(\mathrm{n}=4,5,6,7)$. The reduction of the stabilization energy seems to be caused not exclusively by a geometrically hindered resonance stabilization, but also to a smaller extent by a less efficient inductive stabilization in the substituted cyclopropyl carbanions.

\section{Acknowledgments}

This work has been supported financially by the Netherlands Organization for Scientific Research (SON/NWO). The authors thank Drs. T. J. van Diepen and Mrs. Drs. N. P. J. Zenden for their assistance in the experimental work.

\section{References}

1. Hopkinson, A.C.; Lien, M.H. Int. J. Quantum Chem. 1980, $18,1371$.

2. Chandrasekhar, J.; Andrade, J. G.; von R. Schleyer, P. J. Am. Chem. Soc. 1981, 103, 5609.

3. von R. Schleyer, P.; Chandrasekhar, J.; Kos, A. J.; Clark, T.; Spitznagel, G.W. J. Chem. Soc., Chem. Commun. 882, 1981.

4. Pross, A.; DeFrees, D.J.; Levi, B. A.; Pollack, S.K.; Radom, L.; Hehre, W. J. J. Org. Chem. 1981, 46, 1693.

5. Spitznagel, G.W., Clark, T.; Chandrasekhar, J.; von R. Schleyer, P. J. Comput. Chem. 1982, 3, 363.

6. Moffat, J. B. Int. J. Quantum Chem. 1982, 22, 299.

7. Moffat, J. B. I. Am. Chem. Soc. 1982, 104, 3949.

8. Hopkinson, A.C.; McKinney, M. A.; Lien, M.H. J. Comput. Chem. 1983, 4, 513.

9. Clark, T.; Chandrasekhar, J; Spitznagel, G.W; von R. Schleyer, P. I. Comput. Chem. 1983, 3, 294.

10. Lien, M.H.; Hopkinson, A.C.; McKinney, M.A. J. Mol. Struct. (Theochem) 1983, 105, 37.

11. Edgecomb, K.E.; Boyd, R. J. Can. J. Chem. 1983, 61, 45.

12. Edgecomb, K. E.; Boyd, R. J. Can. J. Chem. 1984, 62, 2887.

13. von R. Schleyer, P.; Clark, T.; Kos, A.J.; Spitznagel, G.W.; Rohde, C.; Arad, D.; Houk, K.N.; Rondan, N.G. I. Am. Chem. Soc. 1984, 106, 6467.

14. Kaneti, J;; von R. Schleyer, P.; Clark, T.; Kos, A. J.; Spitznagel, G.W.; Andrade, J. G.; Moffat, J.B. J. Am. Chem. Soc. 1986, 108, 1481.

15. Hehre, W. J.; Radom, L.; von R. Schleyer, P.; Pople, J. A. $A b$ Initio Molecular Orbital Calculations; John Wiley \& Sons: New York, 1986, and references cited therein.

16. Moran, S.; Ellis, Jr., H.B.; DeFrees, D.J.; McLean, A.D.; Ellison, G.B. J. Am. Chem. Soc. 1987, 109, 5996.

17. Moran, S.; Ellis, Jr., H. B.; DeFrees, D.J.; McLean, A.D.; Paulson, S. E; Ellison, G.B. J. Am. Chem. Soc. 1987, 109, 6004 .

18. Bannon, P.E.O.; Dailey, W.P. J. Am. Chem. Soc. 1989, 111, 9244.

19. Dahlke, G. D.; Kass, S. R. J. Am. Chem. Soc. 1991, 113, 5566.

20. Suno, H.; Kass, S. K. J. Am. Chem. Soc. 1992, 114, 1244.

21. Bartmess, J. E.; Wilson, B.; Sorensen, D. N.; Bloor, J. E. Int. J. Mass Spectrom. Ion Processes 1992, 117, 557.

22. Chou, P. K.; Dahlke, G.D.; Kass, S.R. J. Am. Chem. Soc. 1993, 115, 315.

23. Peerboom, R.A. L.; Rademaker, G. J.; de Koning, L. J.; Nibbering, N.M.M. Rapid Commun. in Mass Spectrom. 1992, 6,394 .

24. de Koning, L. J.; Nibbering, N. M. M. J. Am. Chem. Soc. 1987, 109, 1715 and references cited therein.

25. de Koning, L. J.; Kort, C.W. F.; Pinkse, F.A.; Nibbering, N.M. M. Int. J. Mass Spectrom, Ion Processes 1990 95, 93.

26. Bartmess, I. E.; Georgiadis, R.M. Vacuum 1983, 33, 149.

27. Miller, K. J. J. Am. Chem. Soc. 1990, 112, 8533.

28. Furniss, B.S.; Hannaford, A.J.; Smith, P.W.G.; Tatchell, A. R. Vogel's Textbook of Practical Organic Chemistry; Longman Scientific \& Technical: New York, 1959.

29. Lampman, G.M.; Horne, D. A.; Hager, G. D. I. Chem. Eng. Data 1969, 14, 396.

30. (a) Iffland, D.C.; Criner, G.X.; Koral, M.; Lotspeich, F. J.; Papanastassiou, Z. B.; White, S.M. J. Am. Chem. Soc. 1953, 75, 4044. (b) Amrollah-Madjdabadi, A.; Beugelmans, R.; Lechevallier, A. Synthetic Communications 1986, 826.

31. Lias, S. G.; Bartmess, J. E.; Liebman, J. F.; Holmes, J. L.; Leven, R. D.; Mallard, W.G. J. Phys. Chem. Ref. Data 17 1988, Suppl. 1.

32. Andrist, A.H.; DePuy, C.H.; Squires, R. R. I. Am. Chem. Soc. 1984, 106, 845. 
33. Meot-Ner, M.; Kafafi, S. A. I. Am. Chem. Soc. 1988, 110, 6297.

34. Han, C.C.; Brauman, J. I. I. Am. Chem. Soc. 1989, 111, 6491.

35. Chou, P. K.; Kass, S. R. Org. Mass Spectrom. 1991, 26, 1039.

36. Dawson, J.H.Y.; Nibbering, N.M.M. Int. J. Mass Spectrom. Ion Phys. 1980, 33, 3.

37. Matimba, H.E. K.; Crabbendam, A. M.; Ingemann, S.; Nibbering, N.M. M. Int. J. Mass Spectrom. Ion Processes 1992, 114,85 .

38. van der Wel, II; Nibbering, N.M.M. Recl. Trav. Chim. Pays-Bas 1988, 107, 479 and 491.
39. Bartmess, J. E.; Scott, J.A.; Mclver, Jr., R.T. J. Am. Chem. Soc. 1979, 101, 6046

40. Taft, R. W.; Topsom, R. D. Prog. Phys. Org. Chem. 1987, 16, 1.

41. Topsom, R, D. Prog. Phys. Org. Chem. 1987, 16, 125.

42. Taft, R.W.; Abboud, J. L. M.; Anvia, F.; Berthelot, M.; Fujio, M.; Gal, J.-F.; Headly, A. D.; Henderson, W.G.; Koppel, 1.; Qian, J.H.; Mishima, M.; Taagepera, M.; Ueji, S. I. Am. Chem. Soc. 1988, 110, 1797.

43. Taft, R.W.; Koppel, I. A.; Ropsom, R. D; Anvia, F. I. Am. Chem. Soc. 1990, 112, 2047. 